\title{
Pulmonary Valve
}

National Cancer Institute

\section{Source}

National Cancer Institute. Pulmonary Valve. NCI Thesaurus. Code C12775.

A valve that is located between and controls the flow of blood from the right ventricle of the heart and the pulmonary artery. 